\title{
DIAGNOSIS OF DAMAGE TO THE VENTILATION SYSTEM
}

\author{
Orest VOZNYAK ${ }^{1}$, Nadiia SPODYNIUK ${ }^{2}$, Iryna SUKHOLOVA ${ }^{1}$, Oleksandr DOVBUSH ${ }^{1}$, \\ Mariana KASYNETS ${ }^{1}$, Oleksandra DATSKO ${ }^{3}$ \\ ${ }^{1}$ Lviv Polytechnic National University, Department of Heat and Gas Supply and Ventilation \\ St. Bandery, 12, 79013, Lviv - 13, Ukraine, e-mail: orest.voznyak @i.ua \\ ${ }^{2}$ National University of Life and Environmental Sciences of Ukraine, \\ Department of Heat and Power Engineering, \\ Heroyiv Oborony Str., 12, 03041, Kyiv, Ukraine, e-mail: $\underline{n}$ spoduniuk@meta.ua \\ ${ }^{3}$ Lviv Polytechnic National University, Department of Civil Safety \\ St. Bandery, 12, 79013, Lviv - 13, Ukraine, e-mail: dacko_lp@ukr.net,
}

\begin{abstract}
The article is devoted to solving of urgent problem to eliminate damages of two types in ventilation systems for air distribution efficiency increasing in the premises by swirled air flow, compact air jet, flat air stream and rectangular air jet. A mathematical model of air supply with swirled air flow, compact air jet, flat air jet and rectangular air stream in the room has been developed. It is shown that in order to achieve the maximum efficiency of air distribution it is necessary to ensure its supply by jets. Graphical and analytical dependences on the basis of the conducted experimental research are presented. Parameters of swirled air flow, compact air jet, flat air stream and rectangular air jet during the formation of a comfortable indoor climate are determined. The results of experimental studies of air supply to the room by the air distribution devices, which form a swirled air flow, compact air stream, flat air flow and rectangular air jet with adequate turbulence and long range of the supply air flow, are presented. It is established that with the increase of the angle of swirling plates inclination and ratio of the slit sides the air jets long range increases.
\end{abstract}

Keywords: air distribution, damages, swirled air jet, compact air jet, flat air jet.

\section{INTRODUCTION}

One of the important tasks of room ventilation is to ensure the effective organization of air exchange [6], in particular air distribution [2, 4, 12]. In this case, the requirements of ensuring the normalized velocity and temperature of the air in the working area $[14,16,18]$ and energy efficiency $[9,37,39]$ should be followed. Exhaust air utilization by recuperators is usually used $[1,36]$. Sometimes the production process takes place in small premises, overloaded with technological equipment and personnel [38]. In this case, there is a need to ensure the supply of a large amount of fresh air in the compressed conditions of these premises. This makes it impossible to provide a normalized air velocity in the working area $[17,21$, 27,33 ]. The velocity of air flows usually exceeds the normalized values, because it does not provide effective attenuation of the air jets velocity $[5,7$, 10]. The rate of attenuation is caused by viscosity as a physical property of air. The quantitative characteristic of the attenuation of the air flow velocity is the corresponding velocity attenuation coefficient, which is denoted by $m$. Due to the selfsimilarity properties, the thermal properties of the air jet are consistent with the dynamic and are similarly characterized by the attenuation of the air flow temperature. The temperature attenuation is also determined by the characteristic temperature attenuation coefficient and is denoted by $n$. The attenuation coefficients of velocity and temperature are dimensionless and describe the behavior of the air flow as it flows out of the air distributor at the initial and main section of the air jet. If the values of the attenuation coefficients are high, it indicates insufficient flow turbulence, insufficient attenuation of velocity and temperature, and a significant advantage of dynamic forces over friction forces (viscosity). However, air distributors have a low coefficient of aerodynamic resistance, which is a positive factor in the energy aspect.

The attenuation of the air flow rate is directly related to its long range. The long range of the air stream is the maximum distance that the air flow travels during its development from the air distributor to the point where the velocity of the direct flow becomes equal to the mobility of air in the room, and the air stream is transformed from the direct flow to the reverse one. At the same time the long range of the air jet becomes too high and needs to be reduced. When the normative values of air velocity and temperature are exceeded, the conditions of comfort are violated [24]. This phenomenon means that the ventilation system has a damage type 1 .

There is another problem of formation of stagnant unventilated areas in the room due to 
insufficient air jets long-range since the intense air velocity attenuation. In this case, the values of the attenuation coefficients are too low. This indicates excessive flow turbulence, excessive attenuation of air velocity and temperature, and a significant advantage of friction (viscosity) over dynamic forces. As a result, air distributors have a high coefficient of aerodynamic resistance, which negatively affects the ventilation system as a whole, as it becomes energy consuming [25]. This results in the fact that the long range of the air jet becomes too low and needs to be increased. The consequence of this is an excessive concentration of $\mathrm{CO}_{2}$ in the room $[13,15,19,20]$. This phenomenon means that the ventilation system has a damage type 2 .

A progressive direction in overcoming damage to the ventilation system of both types is an adequate choice of air distribution devices [3, 23, 34] with the appropriate coefficients of attenuation of air jet velocity and temperature and also achieving proper air jet long range in a premise. Attention should be paid to the distribution of air by compact, flat, rectangular jets and swirled air streams. Ensuring comfort conditions and achieving energy efficiency of air distribution by optimizing the attenuation coefficients of air velocity and temperature and also long range through the use of compact, flat, rectangular and swirled air jets and recuperators is an extremely important task.

\section{GOAL OF THIS PAPER}

The aim of the work is to eliminate damages of two types in ventilation systems due to determine the long range and initial section of flat, compact, rectangular and swirled air jets and to establish graphical and analytical calculation dependences under the condition of creating a comfortable microclimate in the premises.

To achieve this goal it is necessary to perform the following research tasks:

- to analyze the characteristics of flat, compact, rectangular and swirled air jets, their efficiency and design dependencies;

- to generalize and deepen the theory of aerodynamic processes in air supply by flat, compact, rectangular and swirled jet streams;

- to perform experimental studies of air distribution by flat, compact, rectangular and swirled air jets, establish graphical and analytical calculation dependences;

to determine the long range and length of the initial section of flat, compact, rectangular and swirled air jets;

- to compare the theoretically obtained results with experimental data and establish correction factors for the theoretical solution of indoor air distribution.

\section{RESEARCH OF AIR JETS LEAKAGE}

Flat [8, 11], compact [36, 37] and swirled [34, $36,37]$ air jets are one of the most common in ventilation technology. Flat and compact air jets are usually used as horizontal, and swirled - as vertical $[36,37]$. Flat air jets are formed by means of inflow slits with a ratio of length to height $l / b \geq 10$, and with a ratio of $1<l / b<10$ it is expedient to call jets rectangular. Compact jets are formed by round or square holes. Swirled air jets are formed due to the presence in the cylindrical hole of the swirling plates, which can be deviated at a certain angle $\alpha$. This is an important factor that determines the properties and characteristics of these jets. As a result, they have different coefficients of air velocity and temperature attenuation, aerodynamic resistance, acoustic properties of aerodynamic noise [35], and especially the long range of the jet and its initial section. In particular, it would be interesting to compare the long range of flat, compact and rectangular air jets depending on the ratio of the sides of the supply slit $l / b$ and swirled air stream depending on the angle of the swirling plate's inclination $\alpha$.

Based on the analysis, it should be stated that the long range of air jets is directly affected by the air velocity attenuation coefficient, which depends on the aerodynamic resistance. Among them the flat air jets have the highest aerodynamic resistance and compact air jets have the lowest. This is a consequence of a sudden narrowing of the jet when it enters the cross section of the air outlet. Due to this, the attenuation coefficient of the velocity is lower, which results in to a decrease in the length of the initial section of the supply air jet. However, the corresponding nature of the change in axial velocity indicates the need to take into account the initial velocity of the jet and the size of the supply nozzle to determine the range [29 - 32]. The aerodynamic resistance of the swirled jets depends on the angle of the swirling plates inclination. At smaller angles of the plates inclination more intense turbulence of the inflow is observed, so the resistance increases, and the attenuation coefficient of velocity decreases.

The article presents a generalization of the calculation dependences for determining the long range $x_{\max }$ of the flat, compact, rectangular and swirled air jets and bringing them to a universal form.

Taking into account the hypothesis, we assume the dependence (1) to determine the long range of the flat, compact and rectangular air jets:

$$
x_{\max }=b\left(\frac{v_{0} m}{v_{x}}\right)^{\frac{1}{n}}
$$

where $x_{\max }-$ air jet long range, $\mathrm{m}$;

$b$ - height of a tidal slit, m; 
$m$ - velocity attenuation coefficient, which depends on the ratio of the length of the tidal slit to its height $l / b$;

$n$ - an indicator of degree, which depends on the ratio of the length of the tidal hole to its height $l / b$

$v_{0}$ and $v_{x}$ - respectively, the absolute initial and axial velocity of the air stream, $\mathrm{m} / \mathrm{s}$.

Taking into account [36], the long range of the swirled air jets is determined by dependence (2):

$$
x_{\max }=\frac{v_{0} m k_{s w} \sqrt{\pi} D}{2 v_{x}}
$$

where $x_{\max }$ - air jet long range, $\mathrm{m}$;

$D$ - diameter of the inlet nozzle, $\mathrm{m}$;

$m$ - air velocity attenuation coefficient, which depends on the angle of the swirling plates inclination $\alpha$ and is determined from [36];

$k_{s w}$ - a swirling coefficient which depends on the angle of the swirling plates inclination $\alpha$ and is determined from [36]; $v_{0}$ and $v_{x}$ - respectively, the absolute initial and axial velocity of the air stream, $\mathrm{m} / \mathrm{s}$.

Experimental studies have been carried out on the installation shown in Fig. 1 under the following conditions and simplifications:

- the area of openings $F_{0}=0.009-0.010 \mathrm{~m}^{2}$;

- air flow rate was within the range

$$
L=100-500 \mathrm{~m}^{3} / \mathrm{h} \text {; }
$$

- the initial air velocity was within $v_{0}=2-6 \mathrm{~m} / \mathrm{s}$;

- the ratio of the sides of the tidal slit: $l / b=10 ; 5$; $2.5 ; 1$;

- $\quad$ angle of swirling plates inclination: $\alpha=15^{\circ}$, $\alpha=30^{\circ}, \alpha=45^{\circ}, \alpha=60^{\circ}, \alpha=75^{\circ}$;

- diameter of the air distributor with the swirling plates: $D=150 \mathrm{~mm}, D=250 \mathrm{~mm}$.

Air velocity was measured with a thermal electrical anemometer Testo-405 at these values.

The obtained results with respect to axial velocities are presented in Fig. 2.

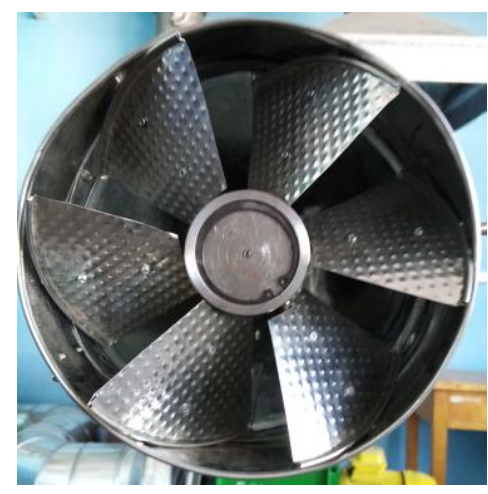

a)

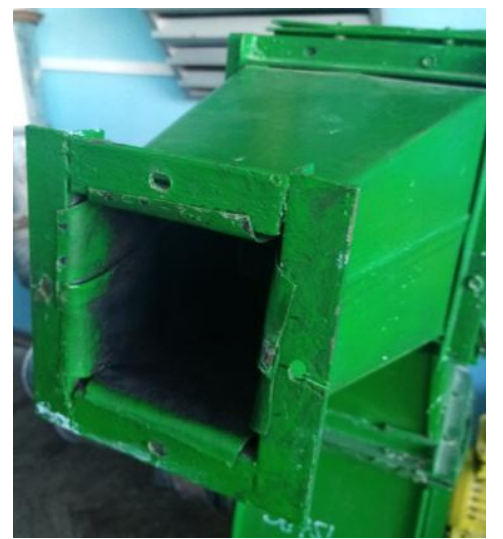

c)

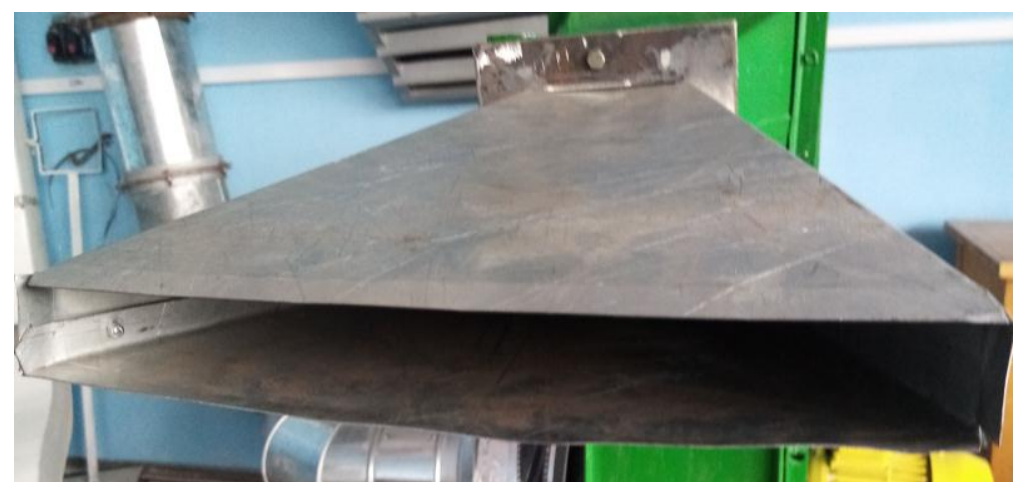

b)

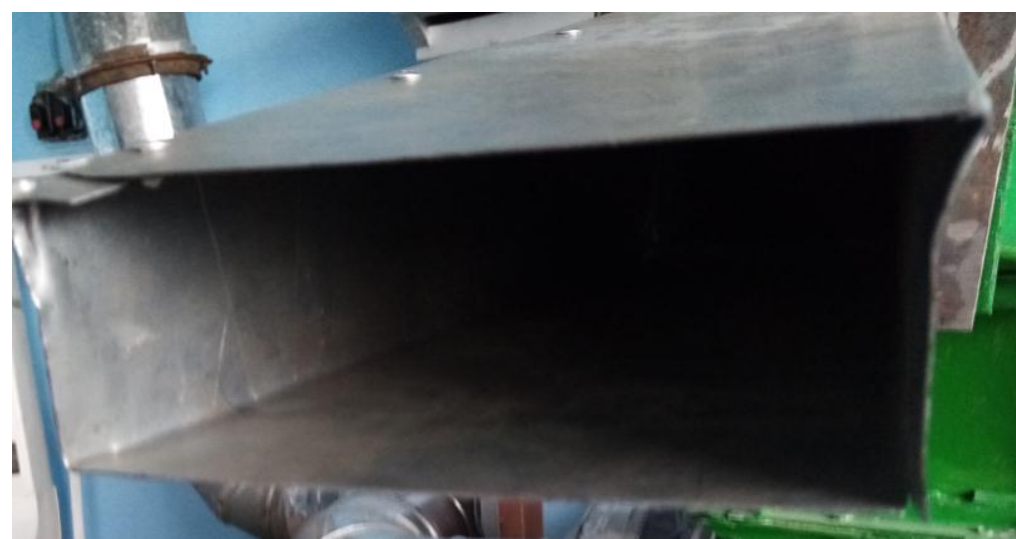

d)

Fig. 1. Experimental installation:

a) - air distributor $D=250 \mathrm{~mm}$ with the swirling plates for a swirled air jet;

b) - slit with the ratio of the sides $l / b=10(30 \times 3 \mathrm{~cm})$ for a flat air jet;

c) - slit with the ratio of the sides $l / b=1(10 \times 10 \mathrm{~cm})$ for a compact air jet;

d) - slit with the ratio of the sides $l / b=2.5(15 \times 6 \mathrm{~cm})$ for a rectangular air jet 


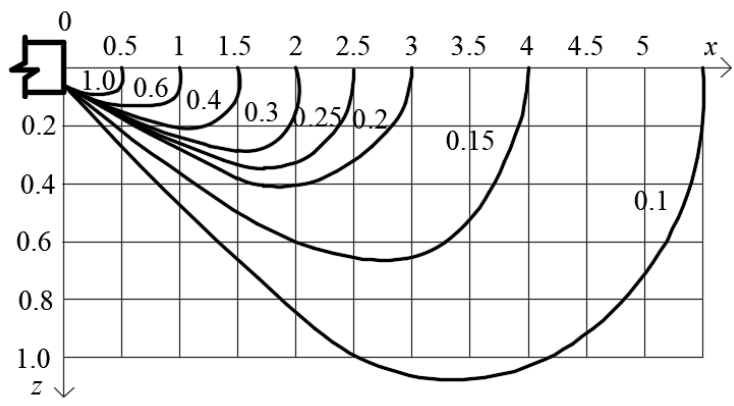

a)

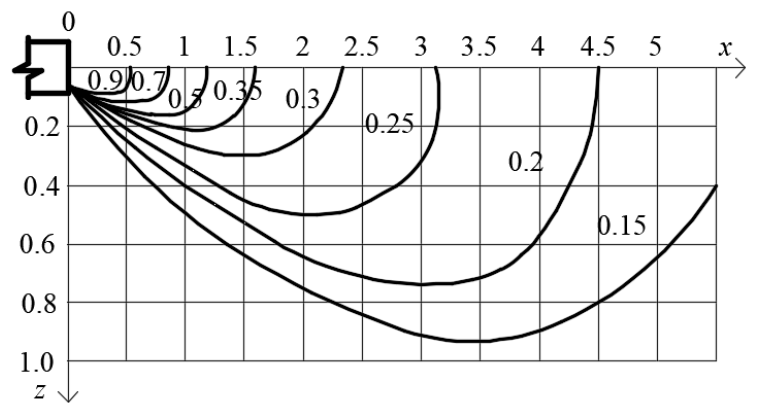

b)

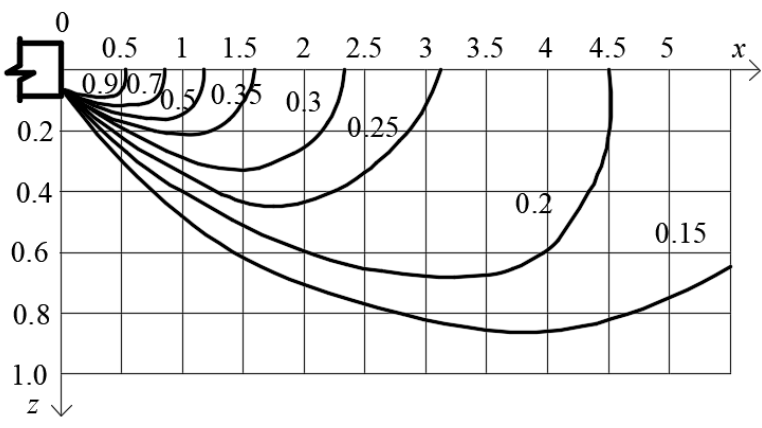

c)

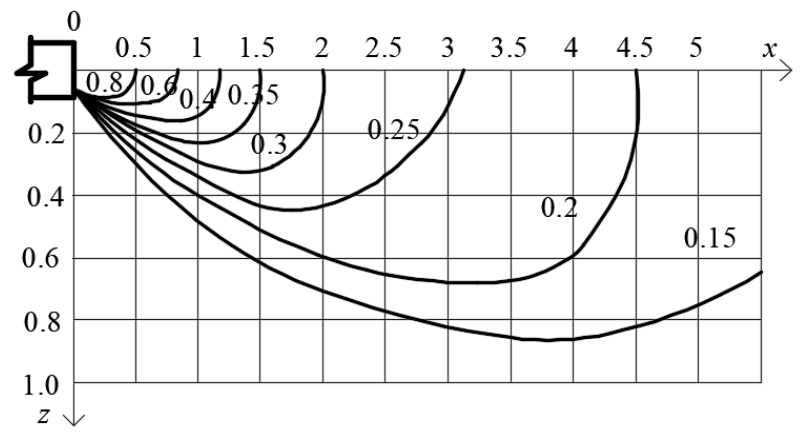

d)

Fig. 2. Relative axial velocities in the longitudinal section of the air jets: a) - slit with the ratio of the sides $l / b=1(10 \times 10 \mathrm{~cm})$ for a compact air jet; b) - slit with the ratio of the sides $l / b=2.5(15 \times 6 \mathrm{~cm})$ for a rectangular air jet; c) - slit with the ratio of the sides $l / b=5(22.5 \times 4.5 \mathrm{~cm})$ for a rectangular air jet; d) - slit with the ratio of the sides $l / b=10(30 \times 3 \mathrm{~cm})$ for a flat air jet

The experimental results (Fig. 2) show that directly at the outlet of the nozzle for rectangular air jets close to the flat (increasing of the slit sides ratio) increases the flow turbulence. At the same time the air velocity attenuates more intensively and the ambient air is ejected. As a result, the long range of the flat air jet increases, and the length of the initial section decreases (Fig. 3). For rectangular air jets close to compact (reduction of the slit sides ratio), the turbulence of the flow is not so intense. In this case, the air velocity attenuates weaker and the ambient air is ejected less intensely, as a result of which the long range of the compact air jet decreases and the length of the initial section increases (Fig. 3).

The graph (Fig. 3) is approximated by a polynomial dependence (3):

$$
x_{i n}=0.1+1.1 \frac{b}{l}-0.6\left(\frac{b}{l}\right)^{2}
$$

For the convenience of the graphic image and analytical approximation, the ratio of the sides dimensions of the flat slit is presented in the form $b / l$.

The results of the swirled air jet study are presented in Fig. 4. Fig. 4 shows that the effect of swirling is manifested as much as possible at smaller angles: the air jet is most affected by the swirling of the air flow, and the axis of the jet changes the direction as much as possible.

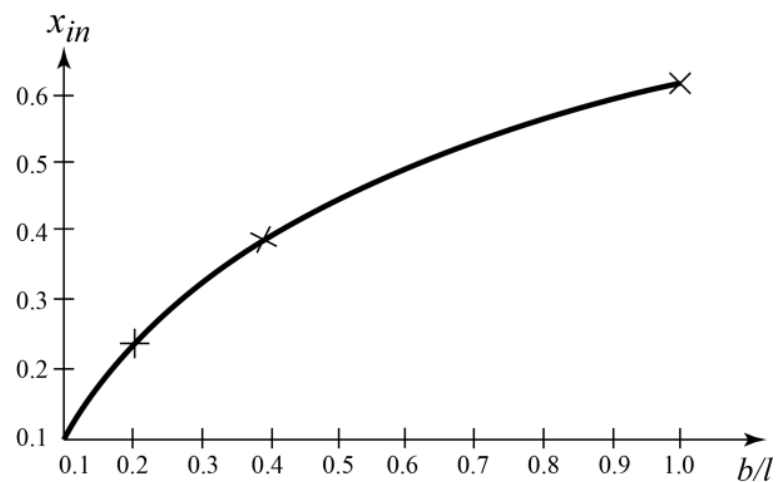

Fig. 3. Dependence of the length of the initial section on the ratio of the sides' dimensions of the flat slit $b / l$

At an angle of the swirling plate's inclination $30^{\circ}$ in the section from $\bar{x}=0.125$ to $\bar{x}=0.250$ the axis of the tidal jet passes at an angle of $18^{\circ}$ to the horizontal, in the section from $\bar{x}=0.250$ to $\bar{x}=0.50$ the axis of the jet passes at an angle of $45^{\circ}$ to the horizontal. Starting from the cross section $\bar{x}=0.50$, the axis of the jet runs parallel to the axis of the air distributor and at a distance $\bar{y}=0.50$ from its axis. At an angle of the swirling plate's inclination $60^{\circ}$ in cross section from $\bar{x}=0.125$ to $\bar{x}=0.375$ the axis of the swirled air jet passes along the axis of the air distributor. In cross section from $\bar{x}=0.375$ to $\bar{x}=0.625$ the axis 
of the jet passes at an angle of $45^{\circ}$ to the horizontal.

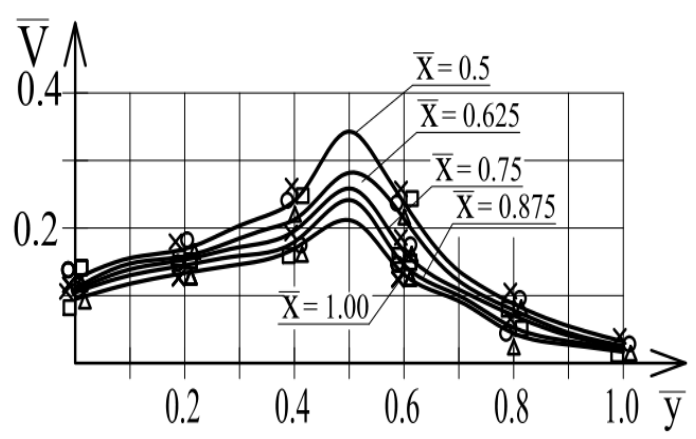

a)

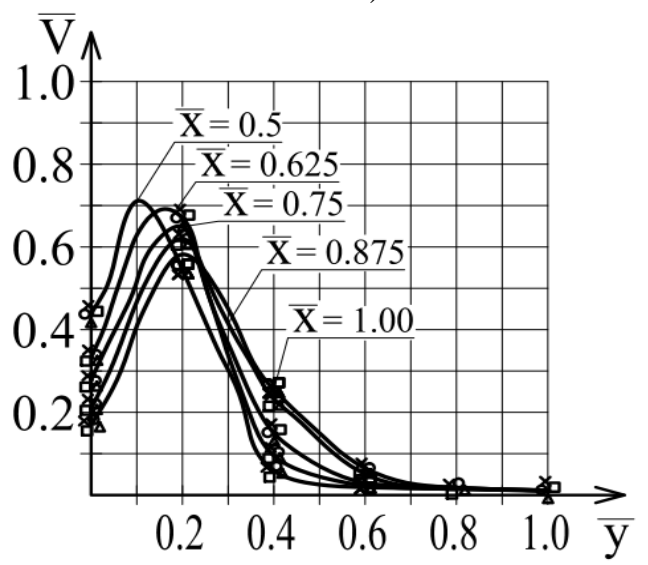

b)

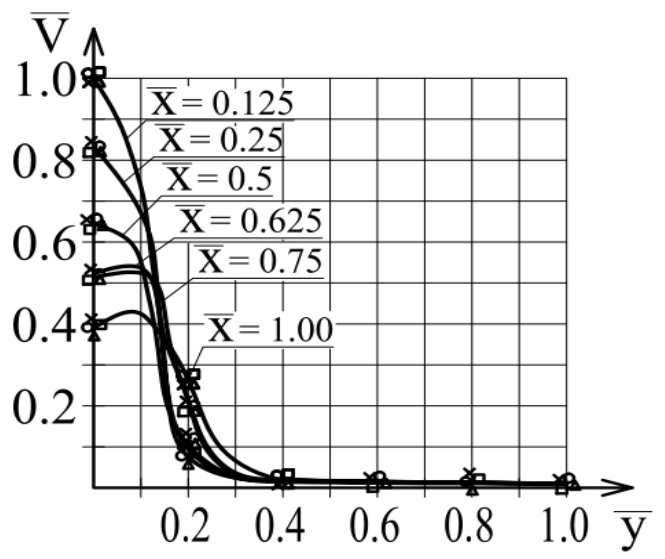

c)

Fig. 4. Graphical dependences of relative velocities on relative distances from the air distributor at angles of swirling plates inclination: a) $30^{\circ}$; b) $60^{\circ}$; c) $90^{\circ}$

Starting from the cross section $\bar{x}=0.625$, the axis of the supply air jet runs parallel to the axis of the air distributor and at a distance $\bar{y}=0.20$ from its axis.

At an angle of the swirling plates inclination $90^{\circ}$, the axis of the air jet coincides with the axis of the air distributor, so air jet is close in its characteristics to the direct flow. At small angles of inclination, the air jet passes the greatest distance from its exit from the air distributor to the working area entrance. Thus there is the most effective mixing of supply air with surrounding one and therefore at such angle of inclination it is possible to supply air with higher initial velocity at exit from the air distributor.

The swirling effect results in to a significant reduction of the initial section length compared to rectangular air jets in general. Increasing of the swirling plates inclination angle results in to increase the length of the initial section and decreasing - according to decrease.

To determine the long-range of tidal air jets was implemented planning a complete three-factor experiment - Table 1, where the determining factors are:

$x_{1}=v_{0}-$ initial air jet velocity, $x_{1}=2-6 \mathrm{~m} / \mathrm{s}$;

$x_{2}=\alpha-$ the angle of the swirling plates inclination, $x_{2}=15^{0}-75^{\circ}$;

$x_{3}=D-$ nozzle diameter, $x_{3}=150-250 \mathrm{~mm}$.

The optimization parameter is the long-range of the air jet $y=x_{\max }, \mathrm{m}$.

Table 1

Planning matrix of a complete 3-factor experiment

\begin{tabular}{|c|c|c|c|c|c|c|c|c|c|}
\hline$№$ & $x_{0}$ & $x_{1}=v_{0}$ & $x_{2}=\alpha$ & $x_{3}=D$ & $x_{1} x_{2}$ & $x_{1} x_{3}$ & $x_{2} x_{3}$ & $x_{1} x_{2} x_{3}$ & $y=x_{\max }$ \\
\hline 1 & + & - & - & - & + & + & + & - & 0.6 \\
\hline 2 & + & + & - & - & - & - & + & + & 1.8 \\
\hline 3 & + & - & + & - & - & + & - & + & 0.9 \\
\hline 4 & + & + & + & - & + & - & - & - & 2.7 \\
\hline 5 & + & - & - & + & + & - & - & + & 1.0 \\
\hline 6 & + & + & - & + & - & + & - & - & 3.0 \\
\hline 7 & + & - & + & + & - & - & + & - & 1.5 \\
\hline 8 & + & + & + & + & + & + & + & + & 4.5 \\
\hline
\end{tabular}

According to the results of experiment planning, we obtain the regression equation (4):

$$
y=2.0+1.0 x_{1}+0.25 x_{2}+0.5 x_{3}
$$

The regression analysis showed that the longrange effect is most affected by the initial air velocity, and the least affected by the angle of the swirling plate's inclination. Long-range increases with increasing all the determining factors: the initial air velocity, the angle of the swirling plates inclination and the diameter of the nozzle.

According to the results of the experiment, a nomogram was constructed (Fig. 5).

Due to graphical dependence (Fig. 5) the direct problem and three inverse problems are solved (the corresponding solution keys are presented in Fig. $5)$. This means that any value from the four ones (the initial velocity $v_{0}$, the angle of the swirling plates inclination $\alpha$, the diameter of the nozzle $D$ and the air jet long range $x_{\max }$ ) is determined if other three are given. This graph (Fig. 5) makes it possible to determine the required long range of the swirled air jet to eliminate damage of both types in the ventilation system. 


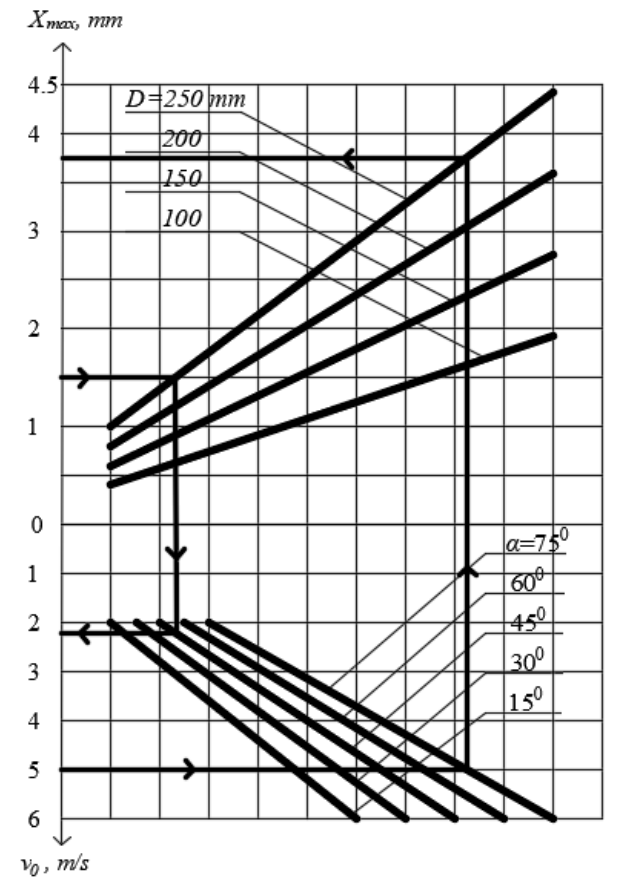

Fig. 5. Interdependence between long-range $x_{\max }$, initial velocity $v_{0}$, angle of inclination $\alpha$ and nozzle diameter $D$

For compact, flat and rectangular air jets, a similar experiment planning matrix is composed with the following determining factors:

$x_{1}=v_{0}-$ initial velocity of the air jet, $x_{1}=2-6 \mathrm{~m} / \mathrm{s}$; $x_{2}=b / l-$ the ratio of the slit height to its length, $x_{2}=0.1-1$; $x_{3}=b-$ slit height, $x_{3}=0.03-0.10 \mathrm{~m}$.

According to the results of experiment planning, it was received the regression equation (5) for longrange as an optimization parameter:

$$
y=6.45+3.225 x_{1}-2.15 x_{2}+3.45 x_{3}
$$

The regression analysis showed that the smallest effect on long-range is the ratio of the sides of the tidal slit, and the effect of the initial velocity and height of the slit is almost equivalent. Long-range increases with increasing initial velocity and slit height, but decreases with increasing ratio of slit height to its length $b / l$.

According to the results of the experiment, a nomogram was constructed (Fig. 6).

Similarly, to Fig. 5 due to graphical dependence (Fig. 6) four problems are solved (direct problem and three inverse problems). The corresponding solution keys are presented in Fig.6. This nomogram (Fig. 6) makes it possible to determine the required long range of the rectangular air jet to eliminate damage of both types in the ventilation system.

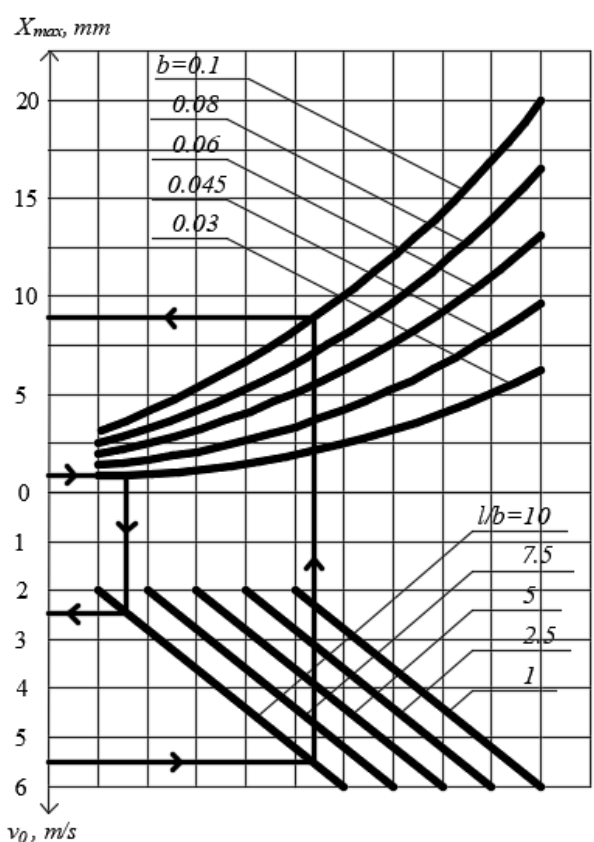

Fig. 6. Interdependence between long-range $x_{\max }$, initial velocity $v_{0}, l / b$ ratio and slit height $b$

\section{CONCLUSIONS}

1. On the basis of the conducted research graphic and analytical dependences for determination of long-range $x_{\max }$ and length of initial section $x_{\text {in }}$ of flat, compact, rectangular and swirled air streams are received and they are brought to a universal form. The ability to choose the long range of air jets allows us to eliminate damage type 1 to the ventilation systems.

2. Graphical and analytical dependences for determination of air velocities of the flat, compact, rectangular and swirled inflow air jets under the condition of creating a comfortable microclimate indoors are obtained. This eliminates type 2 damage to ventilation systems.

3. The hypothesis of air jets long range and length of the initial section of the flat, compact, rectangular and swirled air jets is experimentally confirmed.

4. The regression analysis showed that the long range of the swirled jets is most affected by the initial velocity, and the least affected by the angle of the swirling plate's inclination. Longrange increases with increasing all the determining factors: the initial air velocity, the angle of the swirling plates inclination and the diameter of the nozzle. The smallest effect on the range of rectangular air jets has the ratio of the sides of the tidal slit, and the effect of the initial air velocity and height of the hole is almost equivalent. Long range increases with increasing initial velocity and slit height, but decreases with increasing the ratio of slit height to its length $b / l$. These results make it possible 
to eliminate damage of both types in ventilation systems.

5. The graphical way of the decision of four problems (direct and three inverted) in the form of the corresponding keys of the decision for the swirled, flat, compact and rectangular air streams is presented.

\section{REFERENCES}

1. Adamski M. Ventilation system with spiral recuperator. Energy and Buildings. 2010; 42(5): 674677. https://doi.org/10.1016/j.enbuild.2009.11.005.

2. Allmaras SR. Multigrid for the 2-D Compressible Navier-Stokes Equations. 14th Computational Fluid Dynamics Conference. American Insitute of Aeronautics and Astronautics: Norfolk USA, 1999. https://doi.org/10.2514/6.1999-3336.

3. Andersson H, Cehlin M, Moshfegh B. Experimental and numerical investigations of a new ventilation supply device based on confluent jets. Building and Environment. 2018;137:18-33.

https://doi.org/10.1016/j.buildenv.2018.03.038.

4. Coleman GN, Rumsey CL, Spalart PR. Numerical study of turbulent separation bubbles with varying pressure gradient and Reynolds number. Journal of Fluid Mechanics. 2018;847:28-70.

https://doi.org/10.1017/jfm.2018.257.

5. Dovhaliuk V, Gumen O, Mileikovskyi V, Dziubenko V. Simplified analysis of turbulence intensity in curvilinear wall jets. FME Transactions 2018; 46: 177-182. https://doi.org/10.5937/fmet1802177D.

6. Dovhaliuk V, Mileikovskyi V. New approach for refined efficiency estimation of air exchange organization. International Journal of Engineering and Technology (UAE). 2018; 7(3.2): 591-596. https://doi.org/10.14419/ijet.v7i3.2.14596.

7. Gumen O, Dovhaliuk V, Mileikovskyi V. Geometric representation of turbulent macrostructure in 3D jets. ICGG 2018. Proceedings of the 18-th International Conference on Geometry and Graphics. 2019; 739745. https://doi.org/10.1007/978-3-319-95588-9_61.

8. Gumen O, Dovhaliuk V, Mileikovskyi V, Lebedieva O, Dziubenko V. Geometric analysis of turbulent macrostructure in jets laid on flat surfaces for turbulence intensity calculation. FME Transaction. 2017;45:236-242. https://doi.org/10.5937/fmet1702236G.

9. Gumen O, Spodyniuk N, Ulewicz M, Martyn Y. Research of thermal processes in industrial premises with energy-saving technologies of heating. Diagnostyka. 2017; 18(2): 43 - 49.

10. Hnativ R, Verbovskiy O. Distribution of local velocities in a circular pipe with accelerating fluid flow. Eastern-European Journal of Enterprise Technologies. 2019;2(7-98):58-63. https://doi.org/10.15587/1729-4061.2019.162330.

11. Hulai B, Dovbush O, Piznak B, Kasynets M. Studying Equalization of the Radial Fans Discharge Flow. Lecture Notes in Civil Engineering. 2020; 47: 119-126. https://doi.org/10.1007/978-3-030-270117_15.

12. Janbakhsh S, Moshfegh B. Experimental investigation of a ventilation system based on wall confluent jets. Building and Environment. 2014;80: 18-31.https://doi.org/10.1016/j.buildenv.2014.05.011.
13. Kapalo P, Domnita F, Bacotiu C, Podolak M. The influence of occupants' body mass of carbon dioxide mass flow rate inside of university class-room - case study. International Journal of Environmental Health Research. 2018;28(4):432-447. https://doi.org/10.1080/09603123.2018.1483010.

14. Kapalo P, Klymenko H, Zhelykh V, Adamski M. Investigation of Indoor Air Quality in the Selected Ukraine Classroom - Case Study. Lecture Notes in Civil Engineering 2020; 47: 168-173.

15. Kapalo P, Meciarova L, Vilcekova S, Burdova E, Domnita F, Bacotiu C., Peterfi K. Investigation of $\mathrm{CO}_{2}$ production depending on physical activity of students. International Journal of Environmental Health Research. 2019;29(1):31-44. https://doi.org/10.1080/09603123.2018.1506570.

16. Kapalo P, Sedláková A, Košicanová D, Voznyak O, Lojkovics J, Siroczki P. Effect of ventilation on indoor environmental quality in buildings. The 9th International Conference "Environmental Engineering". Vilnius, Lithuania. Selected Papers 2014. https://doi.org/10.3846/enviro.2014.265.

17. Kapalo P, Spodyniuk N. Effect of the variable air volume on energy consumption - Case study. IOP Conference Series: Materials Science and Engineering. 2018;415(1):012027. https://doi.org/10.1088/1757-899X/415/1/012027.

18. Kapalo P, Vilceková S, Domnita F, Voznyak O. Determine a methodology for calculating the needed fresh air. The 9th International Conference "Environmental Engineering". Vilnius, Lithuania. Selected Papers. Section: Energy for Buildings. 2014. https://doi.org/10.3846/enviro.2014.264.

19. Kapalo P, Vilceková S, Domnita F, Bacotiu C, Voznyak O. Determining the ventilation rate inside an apartment house on the basis of measured carbon dioxide concentrations. The 10-th International Conference "Environmental Engineering". Vilnius, Lithuania. Selected Papers. 2017;30-35. https://doi.org/10.3846/enviro.2017.262.

20. Kapalo P, Vilcekova S, Voznyak O. Using experimental measurements, the concentrations of carbon dioxide for determining the intensity of ventilation in the rooms. Chemical Engineering Transactions. 2014;39:1789-1794. https://doi.org/10.3303/CET1439299.

21. Kapalo P, Voznyak O, Yurkevych Yu, Myroniuk $\mathrm{Kh}$, Sukholova I. Ensuring comfort microclimate in the classrooms under condition of the required air exchange. Eastern European Journal of Enterprise Technologies. 2018;5/10(95):6-14. https://doi.org/10.15587/1729-4061.2018.143945.

22. Klymenko H, Labay V, Yaroslav V, Gensetskyi M. Criterial Equation for the Description of Low-Speed Air Distributor Operation. Lecture Notes in Civil Engineering. 2020;47:235-242. https://doi.org/10.1007/978-3-030-27011-7 30.

23. Korbut V, Voznyak O, Myroniuk Kh, Sukholova I, Kapalo P. Examining a device for air distribution by the interaction of counter non-coaxial jets under alternating mode. Eastern European Journal of Enterprise Technologies. 2017; 8(86): 30-38. https://doi.org/10.15587/1729-4061.2017.96774.

24. Labay V, Dovbush O, Yaroslav V, Klymenko H. Mathematical modeling of a split-conditioner operation for evaluation of exergy efficiency of the R600A refrigerant application. Mathematical Modeling and Computing. 2018; 5(2): 169-177. https://doi.org/10.23939/mmc2018.02.169. 
25. Labay VY, Savchenko OO, Zhelykh VM, Kozak KR. Mathematical modelling of the heating process in a vortex tube at the gas distribution stations. Mathematical Modeling and Computing. 2019; 6(2): 311-319. https://doi.org/10.23939/mmc2019.02.311.

26. Labay VY, Yaroslav VY, Dovbush OM, Tsizda AY. Mathematical modeling of an air split-conditioner heat pump operation for investigation its exergetic efficiency. Mathematical Modeling and Computing. 2020;7(1):169-178. https://doi.org/10.23939/mmc2020.01.169.

27. Lis A, Spodyniuk N. The quality of the microclimate in educational buildings subjected to thermal modernization. E3S Web of Conferences. 2019; 100: 00048.

https://doi.org/10.1051/e3sconf/201910000048.

28. Lorin E. From structured data to evolution linear partial differential equations. Journal of Computational Physics. 2019; 393: 162-185. https://doi.org/10.1016/j.jcp.2019.04.049.

29. Lorin E, Benhajali A, Soulaimani A. Positivity Preserving Finite Element-Finite Volume Solver for The Spalart-Allmaras Turbulence Model. Computer Methods in Applied Mechanics and Engineering. 2007;196(17-20):2097-2116.

https://doi.org/10.1016/j.cma.2006.10.009.

30. Rumsey CL, Spalart PR. Turbulence Model Behavior in Low Reynolds Number Regions of Aerodynamic Flowfields. AIAA Journal. 2009; 47(4): 982-993. https://doi.org/10.2514/1.39947.

31. Spalart PR, Garbaruk AV. The Predictions of Common Turbulence Models in a Mature Vortex. Flow, Turbulence and Combustion. 2019; 102: 667677. https://doi.org/10.1007/s10494-018-9983-6.

32. Spodyniuk N, Gulai B, Zhelykh V, Shapoval S. Leveling of pressure flow of radial ventilator in mine ventilation system. Naukovyi Visnyk Natsionalnoho Hirnychoho Universytetu. 2019; 6: 80-86. https://doi.org/10.29202/nvngu/2019-6/12.

33. Tkachenko T, Mileikovskyi V. Increasing indoor air quality by a natural sanitizing interior. The $1^{\text {st }}$ JESSD Symposium: International Symposium of Earth, Energy. Environmental Science and Sustainable Development. 2020;211:1-8.

https://doi.org/10.1051/e3sconf/202021102015.

34. Voznyak O, Korbut V, Davydenko B, Sukholova I. Air distribution efficiency in a room by a two-flow device. Springer, Proceedings of CEE 2019. Advances in Resourse-saving Technologies and Materials in Civil and Environmental Engineering. 2019; 47: 526-533. https://doi.org/10.1007/978-3030-27011-7_67.

35. Voznyak O, Myroniuk K, Sukholova I, Kapalo P. The impact of air flows on the environment. Springer, Proceedings of CEE 2019. Advances in Resoursesaving Technologies and Materials in Civil and Environmental Engineering. 2019; 47: 534-540. https://doi.org/10.1007/978-3-030-27011-7 68.

36. Voznyak O, Spodyniuk N, Yurkevych Yu, Sukholova I, Dovbush O. Enhancing efficiency of air distribution by swirled-compact air jets in the mine using the heat utilizators. Naukovyi Visnyk Natsionalnoho Hirnychoho Universytetu. 2020; 5(179):89-94. https://doi.org/10.33271/nvngu/20205/089.

37. Voznyak O, Sukholova I, Myroniuk K. Research of device for air distribution with swirl and spread air jets at variable mode. Eastern European Journal of
Enterprise Technologies. 2015;6/7(78):15-23. https://doi.org/10.15587/1729-4061.2015.56235.

38. Voznyak O, Yurkevych Yu, Dovbush O, Serediuk Ya. The influence of chairs and passengers on air velocity in bus passenger compartment. Springer, Proceedings of CEE 2019. Advances in Resoursesaving Technologies and Materials in Civil and Environmental Engineering. 2019;47:518-525. https://doi.org/10.1007/978-3-030-27011-7 66.

39. Zhelykh V, Ulewicz M, Spodyniuk N, Shapoval S, Shepitchak V. Analysis of the processes of heat exchange on infrared heater surface. Diagnostyka. 2016; 17(3): 81-85.

Received 2021-05-17

Accepted 2021-09-02

Available online 2021-09-03

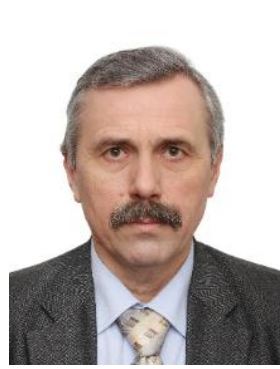

Orest VOZNYAK

Received his MSc (1983) in Building, PhD (1990), DSc (2018) in Technical Sciences.

Currently, he is Professor in the Department of Heat and Gas Supply and Ventilation at Lviv Polytechnic National University, Ukraine.

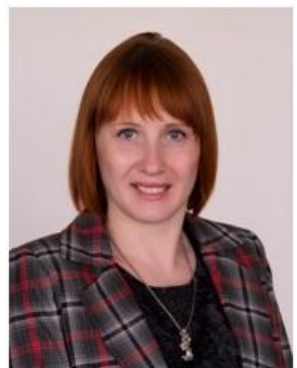

\section{Nadiia SPODYNIUK}

Received her MSc (2007) in Building, PhD (2011). Thesis: Energy efficient Heating provision of the poultry houses. Currently, she is Lecturer in the Department of Heat and Power Engineering at National University of Life and Environmental Sciences of Ukraine.

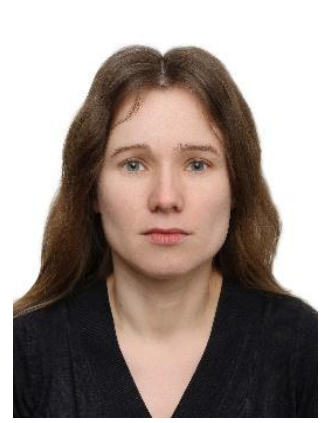

\section{Iryna SUKHOLOVA}

Received her MSc (2007) in Building, PhD (2015). Thesis: Air distribution with swirl and spread air jets in variable regime in production apartments. Currently, she is Lecturer in the Department of Heat and Gas Supply and Ventilation at Lviv Polytechnic National University, Ukraine.

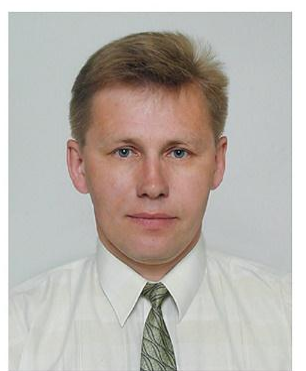

\section{Oleksandr DOVBUSH}

Received his MSc (1984) in Building.

Currently, he is Lecturer in the Department of Heat and Gas Supply and Ventilation at Lviv Polytechnic National University, Ukraine. 


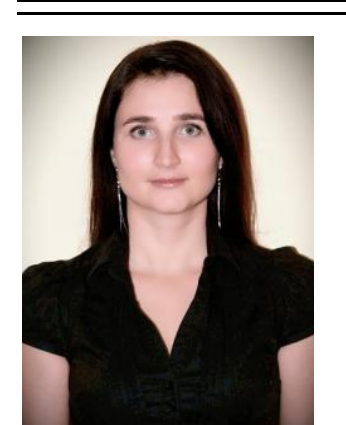

Mariana KASYNETS

Received her MSc (2009)

in Building, PhD (2013).

Thesis: Improvement of

solar panels of periodic

action that are combined

with a cover of buildings.

Currently, she is Lecturer

in the Department of Heat

and Gas Supply and

Ventilation at Lviv

Polytechnic National

University, Ukraine.

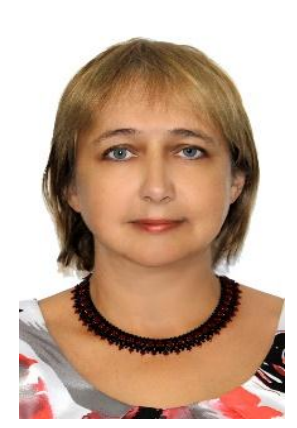

\section{Oleksandra DATSKO}

Received her MSc (1985) in

Building, PhD (1994). Thesis: Improving the efficiency of solar heating systems by discrete orientation of solar collectors. Currently, she is Lecturer in the Department of Civil Safety at Lviv Polytechnic National University, Ukraine. 